(REVIEW ARTICLE)

\title{
Dynamics of the epidemiological and nutritional transition in developing countries and appearance of covid 19: Overview
}

\author{
Hamza Nadjib Merad-Boudia*, Majda Dali-Sahi, Baya Guermouche and Nouria Dennouni-Medjati \\ Department of Biology, Analytical Chemistry and Electrochemistry laboratory, Aboubekr Belkaid University, Tlemcen, \\ 13000, Algeria.
}

Publication history: Received on 27 October 2020; revised on 03 November 2020; accepted on 04 November 2020

Article DOI: https://doi.org/10.30574/wjarr.2020.8.2.0402

\begin{abstract}
The burden of chronic no communicable diseases has increased further, making these diseases the leading cause of death and disease worldwide. The aging of the population and public policies aim to shed light on the debates concerning the issues linked to major demographic changes.

Our review returns to the concept of epidemiological transition, seeks to illustrate its evolution in developing countries and to make the link with the origin and characteristics of the nutritional transition. Then we will discuss the global burden of chronic diseases highly concentrated in developing countries. At the end, a section is devoted to changing the global health landscape with COVID 19 infection.
\end{abstract}

Keywords: Epidemiological Transition; Nutritional Transition; Chronic Non-Communicable Diseases; Urbanization; Covid 19

\section{Introduction}

According to United Nations data for 2010, 5.5\% of the African population is aged 60 and over, while this proportion is double in Asia (9.9\%) and Latin America $(10,0 \%)$, and four times higher in the most developed countries $(18.6 \%$ in North America and $21.7 \%$ in Europe). [1]

Evoking the aging of the population in Africa may therefore seem premature. In fact, the process has already started and should progress quickly.

Africa will not escape the aging of its population due to the lengthening of the lifespan. In Algeria, like other Maghreb countries, significant aging will occur over the coming decades. The median age will be close to that of Japan, which is now the highest in the world (46.5 years). In addition, life expectancy at birth increased from 46.5 years at the end of the 1940 s to 53.3 years at the end of the 1960s-1960s. [2] and to 70 years on the eve of the year 2000 [3] .

This development is accompanied by a gradual change in the prevalence of chronic diseases, which represent the leading cause of death worldwide [4].

These are, today, the major public health challenges facing Algeria, like many countries in the world.

\footnotetext{
${ }^{*}$ Corresponding author: Hamza Nadjib Merad-Boudia

Department of Biology, Analytical Chemistry and Electrochemistry laboratory, Abou bekr Belkaid University, Tlemcen, 13000 Algeria. 
The consequences of these pathologies are felt at the level of individuals, but also in terms of health expenditure and productivity [5], [6], [7], [8], [9].

The loss of production associated with 5 major chronic diseases in the world (cancer, cardiovascular diseases, chronic respiratory diseases, diabetes and mental health) was estimated at \$ 47 trillion for the period 2011-2030 [10].

However, over the past 30 years, many fundamental scientific, clinical and epidemiological works have highlighted the role of nutrition in the determinism of major chronic diseases.

While it is difficult to accurately measure the relative weight of nutritional factors, there are many arguments to suggest that it is important.

A few examples illustrate this point: According to the WHO (World Health Organization) , 25.2\% of total mortality in the world is attributable to a combination of risk factors of nutritional origin, each one representing an important part of this mortality: high blood pressure (16.8\%), high blood sugar (7\%), high cholesterol (5.8\%) and low intake of fruits and vegetables $(2.5 \%)$.

These risk factors contribute to the increase in the number of years of life with a pathology [11].

Many studies now highlight the determining role of nutritional factors in limiting the occurrence of arterial hypertension during aging or at least preventing it.

Some others show that the prevalence of under nutrition is quite high among the elderly.

Taking an interest in their nutrition therefore seems a necessary step towards promoting health in this category of the population.

\section{Concept of epidemiological transition}

One can open the question of "epidemiological transition" from the theory of Abdel Omran as one of the first attempts to explain the changes in the structure of the causes of death that accompany the fall in death rates during the demographic transition in industrialized countries from the 18th century [12].

In 1971 he posited the idea that the process of modernization takes place in all societies in three "ages":

- "the age of pestilence and famine", during which mortality is high and fluctuating, with an average life expectancy of less than 30 years.

- "the age of the decline of pandemics" during which life expectancy increases considerably, going from less than 30 years to more than 50 years.

- And finally, "the age of degenerative diseases and diseases of society", during which the rate of decline in mortality slows down, while the disappearance of infectious diseases increases the visibility of degenerative diseases and diseases "of society "are becoming more and more frequent [12].

In the more general scheme of demographic transition, Omran predicted a general convergence of life expectancies towards a limit depending on the new epidemiological profiles of modern societies [12].

Méslè and Vallin propose to review the evolution of this theory for the developing countries which, having entered the health transition process later, were obviously still at much lower levels of life expectancy than the countries of the North in the early fifties [13], [14].

The authors take stock of the matter with a very thorough literature review. They start from the observation that most of these countries have, however, made immense progress since the Second World War, thus participating in the general movement towards convergence.

Thus, countries such as Korea in Asia, Chile in Latin America or Tunisia in Africa (to name but a few examples) have managed, from the 1950s to the 1990s to very quickly fill most of their behind the countries of the North. 
We are finally witnessing a tremendous convergence towards very high levels of life expectancy [13], [14].

In addition, several events made it possible to discuss the limits of this theory.

In 1995; Shcholikov tries with these authors to better understand the unfavorable evolution of mortality in Russia since the sixties, by comparing it with that observed in two Western countries, France and England, in an article entitled:

"Trends in life expectancy and causes of death from 1970 to 1993 in Russia." They suggest that in the pattern of demographic transition, where Abdel Omran predicted a general convergence of life expectancies, the unfavorable development was linked to the health crisis in Eastern Europe under the combined effects of an aggravation of cardiovascular mortality and a continued expansion of societal diseases, in particular alcoholism and violence [15 ].

In 2002, Caselli evokes with the same authors, the outbreak of AIDS in Africa and the punctures made by wars and other political violence, which, unfortunately are not uncommon in Africa, as a second serious sprain which also seemed to slow down the process. convergence [13], [14].

By studying the model of the epidemiological transition in the United States, Olshansky and al in 1986 [16] proposed in addition to the three phases of Omran, a fourth phase, that of "the age of regression of deaths due to degenerative diseases "and even a fifth phase that of" the age of adopting preventive behaviors "[16].

Rogers and Hackenberg see in this fourth phase a time when individual behaviors have an important and significant influence on health [17]

For Julio Frenk and al, the concept of epidemiological transition turned out to be too narrow and it would be useful to broaden the problem by preferring to the concept of "epidemiological transition" that of "health transition" to encompass not only the evolution of characteristics. Epidemiological health status but also that of the responses of societies to this condition.

The first step would then be the decline of infectious diseases (like Omran). The second stage is characterized by the decline in cardiovascular disease. This theory of health transition thus leaves the door open to other later phases, particularly in the area of cancer [18].

In a recent article, Méslè and Vallin, offer a general review of the epidemiological transition to the health transition, in which this theory seemed to them rather to be reconstructed.

On the one hand, the infectious danger is never completely removed, it is only under control and if the conditions of the fight are unfavorable, there can be setbacks, as Africa dramatically illustrates.

Other hand ; the success obtained in Western countries with regard to cardiovascular diseases since the 1970s is the result of a new strategy, combining high medical technology and changes in individual behavior, particularly in the food sector, to which all societies do not were not necessarily prepared [19].

Maire B, Gartner A, Delpeuch F. from the research institute for development, nutrition, food, and society: (WHO collaborating center) joined Lioret S from FFSA (French Food Safety Agency) to discuss the nutritional transition and its relation to diet-related chronic non-communicable diseases in developing countries.

For this research group, the epidemiological transition process is not linear, but very dynamic and often contextdependent. The main merit of Omran's theory of epidemiological transition is to organize all the facts that characterize the transition from a pre-industrial society to a modern society with, as a corollary in terms of health, the progressive substitution of chronic degenerative diseases. Infectious diseases as the leading cause of death.

There are arguably as many models as there are societies and eras, and the speed of these transitions can vary greatly [20].

It is fitting that in a review of his theory 30 years later, Omran [21] distinguishes three models of epidemiological transition namely:

- The Western model (Europe and North America): Classic model, characterized by a gradual transition in mortality rates. 
- The accelerated model (Japan): Where changes take place quickly and over a short period of time.

- The contemporary, delayed or late model (developing countries): Where the transition is still unfinished.

For some authors, who are interested in the epidemiological transition and the growing burden of non-communicable diseases, this theory remains sufficiently coherent and explains well, despite the limits which are opposed to it, the global increase in cardiovascular diseases with a more marked speed in the developing countries [22], [23].

\section{Definition, origin and characteristics of the nutritional transition}

The nutritional transition is linked to the demographic, health and epidemiological transition described by Omran in the previous section $[12,24]$

Maire and al, note that this process, which is encountered in developing countries, was also experienced by most industrialized countries during the evolution of societies, especially in Europe and the United States from the 19th century. .

In these countries, it was characterized by significant changes in several areas of human life: reduction of physical domestic and industrial tasks; transition from food scarcity to food abundance; increased life expectancy; decline of infectious diseases.... [20]

Inspired by the epidemiological transition ages of Omran [24], Popkin, in 1993 will formulate the theory of nutritional transition [25].

He develops it as a dimension of the epidemiological transition, especially designating all the changes that have occurred in diet and lifestyle underway in developing countries.

Maire and al also discuss the combined effect of citiesurbanization and industrialization, changes in the socio-economic environment and globalization [20], [26].

By studying the nutritional transition and its consequences on health, Popkin proposes five stages:

- The first stage, entitled "food collection", is that of primitive societies. It relates to traditional gathering, hunting and fishing, and characterized by a diet rich in complex carbohydrates and fibers, low in fat, mainly in saturated fat, while polyunsaturated fat is plentiful.

The physical effort required for hunting and gathering is very high and to the detriment of obesity [26].

Very unusual nowadays, this stage can still be found in some developing countries.

Carpaneto and al, in an ethno zoological study on the diversity of mammals and traditional hunting observed this food mode in the population living in tropical forests in Central Africa [27].

Léon and al make the same observation by evaluating traditional hunting practices in a rural Mayan community in Mexico [28].

This stage has also been found among the Australian aborigines [29] and the First Nations of Canada [30].

- Stage 2 of this transition (Famine) is characterized by a very little diversified diet, subject to wide variations and acute periods of food shortages and even famines in some cases.

These vary considerably over time and region [26]. They are mostly found in regions grappling with cyclical or regular natural disasters (drought, earthquake, flooding, ...), and also in regions harboring armed conflicts over long periods of time, such as in Africa.

Obesity remains absent due to the high energy expenditure invested in agriculture. 
- The third age of epidemiological transition will correspond, in terms of nutritional transition, "the age of decline in famines", marked by an increase in the consumption of fruits, vegetables and animal proteins.

Energy expenditure is becoming less and less important and sedentary lifestyle more and more frequent.

- At the fourth age of the epidemiological transition, will correspond to the nutritional transition plan, "the age of chronic non-communicable diseases linked to nutrition", marked by a diet richer in fat, cholesterol and sugar, in addition lower in polyunsaturated fat, vegetable protein and fiber, with a sedentary lifestyle as the most common way of life. In contrast to the first stage.

Finally, the fifth stage of the nutritional transition will correspond to the "age of the adoption of preventive behaviors", marked by the appearance of new dietary behaviors and the increase in energy expenditure through the practice of physical activity.

This change in behavior occurs deliberately when faced with a risk of developing Chronic diseases related to nutrition (CDRN) , or with the aim of improving quality of life [26].

The last three stages of nutritional transition according to Popkin [26], which are also the most frequent, range from alleviation of famine and reduction of malnutrition (stage 3) to the onset and expansion of chronic diseases (stage 4 ), then the return to a healthier lifestyle with a decrease in chronic diseases (stage 5).

Many authors support the fact that it is however difficult to classify developing countries in a specific stage, because several of them are still straddling stages 3 and 4 in which we observe a gradual increase in diversity. Food with the onset of chronic diseases that coexist with persistent malnutrition [31], [32], [33].

This situation of coexistence or double burden of malnutrition, which has been the subject of an abundant literature, continues in stage 4 to reach very high levels, particularly in the countries of Latin America, Asia and Asia. North Africa [34] [32], [35], [36], [33].

It must be said that the last stage of transition does not yet retain the attention of the majority of developing countries, while the WHO has already sounded the alarm for prevention strategies against chronic diseases [37].

\section{Chronic diseases related to nutrition}

This term is the literal translation of an Anglo-Saxon expression popularized by the WHO "non-communicable dietrelated chronic disease", which initially aimed to distinguish between the pathology which arises from toxi-infectious agents present in food contaminated (food poisoning) and that which relates to metabolic disorders, at least partly linked, in the long term, to the mode of food.

Analyzing whom estimates and projections, Manton KG in 1988 studied the global impact of no communicable diseases.

The author shows that the global burden of chronic disease will be heavily concentrated in developing countries [38].

Maire and al are interested in the rise of chronic no communicable diseases linked to food, based on WHO estimates during the year 1988 (analyzed by Manton KG) -1998. They find that the latter have long been the leading cause of death in industrialized countries ( $88 \%$ of deaths), and that they could already be attributed to around $40 \%$ of deaths in developing countries.

Conversely, communicable diseases, especially in childhood, continue to decline, promoting a marked increase in life expectancy in all of these countries. Thus, among these chronic non-communicable diseases, some have a recognized link with diet (hyperlipidemia, non-insulin-dependent diabetes, high blood pressure, diseases, cardiovascular diseases, and certain cancers) and with other lifestyle factors, such as sedentary lifestyle [20].

A consultation of WHO / FAO (world health organization/Food and agriculture organization ) expert group on diet, nutrition and the prevention of chronic diseases took place in Geneva from January 28 to February 1, 2002. This consultation followed up the work of the WHO study group. / FAO which met in 1989 to make recommendations regarding the prevention of chronic diseases and the mitigation of their impact. 
These experts have seen the world since the 1950s as a theater where great changes are taking place, leading to major changes in diets, first in industrial regions and, more recently, in developing countries.

Traditional, largely plant-based diets were quickly replaced by high fat, high energy density diets. Furthermore, diet, while essential for prevention, is only one of the risk factors.

Lack of physical activity, the growing importance of which for health is now recognized, results from an increasingly sedentary lifestyle, in both developing and industrialized countries.

In its 1999 World Health Report, the WHO stated that 85\% of the burden of Chronic diseases related to nutrition was borne by Developed countries [39].

Since then, this burden has increased further, making these diseases the leading cause of death and morbidity worldwide. In 2002 , WHO reported that $60 \%$ of deaths worldwide were attributable to chronic diseases, accounting for $43 \%$ of the global disease burden.

The forecasts for 2020 showed that $73 \%$ of deaths would be attributable to chronic diseases, which would represent $60 \%$ of the global disease burden [40] Chronic diseases, in general and in particular Chronic diseases related to nutrition, have been recognized by the WHO since 2002. Like an epidemic, which now affects both developing countries and developed countries [37].

In the need for global surveillance, $\mathrm{CHOI}$ and al qualify chronic diseases as communicable diseases in terms of risk factors, because modern practices regarding diet and physical activity are risk behaviors that spread across countries and are transferable from one population to another as an infectious disease; they are reflected in morbidity tables around the world [41].

Leeder and al point out that projections relating to mortality due to Chronic diseases related to nutrition in developing countries between 1990 and 2020 show an increase of 120\% for women and 137\% for men, putting developing economies in difficulty in their combating these diseases [42].

In 2005 , of the 58 million deaths, $60 \%$ were attributable to CD, of which $32 \%$ were due to chronic nutrition-related diseases CNRD) [43].

Among the hypotheses put forward to explain this increase in mortality due to CNRDs, there is the inadequacy in the Developed countries of health systems in the management of these diseases, the lack of scientific evidence that may attract the attention of decision-makers and the little interest until recently accorded by the international scientific community on this question.

For proof, until 1996, developing countries had access to less than $10 \%$ of research funds on diseases while they endured $90 \%$ of health problems in the world [44], [45].

\section{Change in the global health landscape with covid 19}

The appearance of COVID 19 jeopardizes the theory of epidemiological transition and the associated projections that were planned. In December 2019, the COVID-19 outbreak caused by the severe acute respiratory syndrome coronavirus 2 (SRAS-CoV-2) was first reported. Similar cases quickly appeared in the world [46], [47], [48]. On January 30, 2020, the WHO declared a public health emergency of international concern and declared the rapidly spreading coronavirus epidemic as a pandemic on March 11,2020 [49]

The virus has reached almost every country in the world, each of which faced this new infection at a different stage of the epidemiological transition. In June 2020, cumulative confirmed cases increased dramatically, as did the number of deaths globally. Urgent and emergency care for patients with COVID-19 required effective drugs to control the disease and stop the pandemic.

Europe and the United States as well as most of the countries which were at an advanced stage of the epidemiological transition (lengthening of the life expectancy and urbanization of the population) suffered the full damage of covid 19. The trance of the over-65s who represent the largest percentage of these populations suffered the most. 
As research around the world has looked at new treatments for no communicable diseases. This new infection distracts attention from a rush to find a new treatment for this new virus.

The COVID 19 pandemic has highlighted the heavy burden that non-communicable diseases, neglected (in particular by the confinement of the population as a solution to fight covid 19) impose on health resources. This should serve as a catalyst for the public authorities to implement more stringent control strategies: Fight against tobacco, alcohol,.... Investments should be targeted in improving physical activity and healthy eating.

The coronavirus has exposed the flaws in the health and support systems for the elderly in many countries. The challenge that should be is to find a compromise between the urbanization of the population, the competition for a new vaccine and the economic cost of confinement.

\section{Conclusion}

The advent of COVID 19 will change the situation in terms of public health.COVID-19 has shown that many of the tools needed to fight Non Communicables Diseases are also those needed to fight this pandemic: disease surveillance, leadership action, robust public health, clear communication and equitable access to resilient universal health systems. COVID-19 could provide new information about the interactions between the immune system and Non Communicables Diseases, and potentially change the way we understand and treat these diseases. It could also generate new long-term disabilities that will increase the burden of Non communicable diseases.

\section{Compliance with ethical standards}

\section{Acknowledgments}

We would like to thank the General Directorate of Scientific Research and Technological Development ( GDSRTD) who made the necessary budget available to PhD students to carry out this research.

\section{Disclosure of conflict of interest}

No direct or indirect interest (of a financial or other nature) with a private, industrial or commercial organization relationship with the subject presented.

\section{References}

[1] UNations. World Population Prospects: The 2010 Revision,. 2011.

[2] Negadi, G., D. Tabutin, and J. Vallin, The fertility of Algerians: level and trends. Population, 1974, ${ }^{\circ} 3$. in The International Coordinating Committee for National Research in Demography (I.C.C.R.D) / WHO, 1974.the population of Algeria Chapter 2: Demographic situation of Algeria. 1974; p. 16.

[3] WHO, world health statistics, chp: World health indicators. Demographic and socio-economic data; 2012; p. 160168.

[4] Alwan A, Armstrong T, Bettcher D, Branca F, Chisholm D, Ezzati M, and al. Global status report on noncommunicable diseases 2010: Description of the global burden of Non communicable diseases, their risk factors and determinants. Geneva, Switzerland: World Health Organization, 2011.

[5] Giorda, C., V. Manicardi, and J. Cabezudo, The impact of diabetes mellitus on healthcare costs in Italy. Expert Review of Pharmacoeconomics\& Outcomes Research, 2011; 11:p. 709-719.

[6] Oldridge, N., Economic burden of physical inactivity: healthcare costs associated with cardiovascular disease. . European Journal of Cardiovascular Prevention \& Rehabilitation, 2008; 15:p. 130-139.

[7] Alwan A, Armstrong T, Bettcher D, Branca F, Chisholm D, Ezzati M . The economic burden of ill health due to diet, physical inactivity, smoking, alcohol and obesity in the UK: an update to 2006-07 NHS costs. Journal of Public Health, 2011; 33:p. 527-535.

[8] arride J, Hopkins R, Leslie W, Morin S, Adachi J, Papaioannou A, and al., The burden of illness of osteoporosis in Canada. Osteoporosis International, 2012; 23:p. 2591-2600. 
[9] Zhuo X, Zhang P, Gregg E, Barker L, Hoerger T, Pearson-Clarke T, and al., A Nationwide Community-Based Lifestyle Program Could Delay Or Prevent Type 2 Diabetes Cases And Save \$ 5.7 Billion In 25 Years. Health Affairs 2012; 31:p. 50-60.

[10] Bloom D, Cafiero E, Jané-Llopis E, Abrahams-Gessel S, and al., The Global Economic Burden of Noncommunicable Diseases, in Geneva: World Economic Forum. 2011.

[11] WHO, 2008-2013 action plan for the global strategy for the prevention and control of non-communicable diseases, in Geneva: World Health Organization. 2009.

[12] Omran, A.R., The epidemiologic transition. A theory of the epidemiology of population change. Milbank Mem Fund Q, 1971; 49 (4) p. 509-38.

[13] Caselli, G., F. Meslé, and J. Vallin, Epidemiologic transition theory exceptions, Genus, 2002; 58 (1):p. 9-52.

[14] Meslé, F. and J. Vallin, Health transition: trends and perspectives,. Medicine, Science, 2000; 16 (11):p. 1161-1171.

[15] Shkolnikov, V., F. Meslé, and J. Vallin, The health crisis in Russia. I. Recent trends in life expectancy and causes of death from 1970 to 1993. Population, 1995; p. 907-943.

[16] Olshansky, S.J. and A.B. Ault, The fourth stage of the epidemiologic transition: the age of delayed degenerative diseases. Milbank Q, 1986; 64 (3):p. 355-91.

[17] Rogers, R.G. and R. Hackenberg, Extending epidemiologic transition theory: a new stage. SocBiol, 1987; 34 (34):p. 234-43.

[18] Frenk J, Bobadilla JL, Stern C, Frejka T, Lozano R. Elements for a theory of the health transition. Health Transit Rev, 1991; 1 (1):p. 21-38.

[19] Meslé, F. and J. Vallin, General review "From epidemiological transition to health transition". Tropical Medicine, 2007; 67:p. 545-551.

[20] Maire B, Lioret S, Gartner A, Delpeuch F. [Nutritional transition and non-communicable diet-related chronic diseases in developing countries]. Sante, 2002; 12 (1):p. 45-55.

[21] Omran, A.R., The Epidemiologic Transition Theory Revisited Thirty Years Later. World Health Statistics Quarterly, 1998; 51(2):p. 99-119.

[22] Gaziano, T.A., Reducing the growing burden of cardiovascular disease in the developing world. Health Aff (Millwood), 2007; 26(1):p. 13-24.

[23] Yusuf S, Reddy S, Ounpuu S, Anand S.. Global burden of cardiovascular diseases: part I: general considerations, the epidemiologic transition, risk factors, and impact of urbanization. Circulation, 2001; 104 (22):p. $2746-53$.

[24] Omran, A.R., The epidemiologic transition: a theory of the epidemiology of population change. 1971. Milbank Q, 2005; 83(4):p. 731-57.

[25] Popkin, B.M., Nutritional Patterns and Transitions. Population and Development Review, 1993; 19(1):p. $138-157$.

[26] Popkin, B.M., An overview on the nutrition transition and its health implications: the Bellagio meeting. Public Health Nutr, 2002; 5(1a):p. 93-103.

[27] Carpaneto, G. and F. Germi, Diversity of mammals and traditional hunting incentral African rain forests. Agriculture,. Ecosystems \& Environment, 1992; 40(1-4):p. 335-54.

[28] 28. León, P. and S. Montiel, Wild Meat Use and Traditional Hunting Practices in a Rural Mayan Community of the Yucatan Peninsula, Mexico. Human Ecology, 2008. 36 (2): p. 249-257.

[29] Bowman, D.M.J.S. and C.J. Robinson, The Getting of the Nganabbarru: Observations and reflections on Aboriginal buffalo hunting in northern Australia. Australian Geographer, 2002: 33(2):p. 191-206.

[30] Dahl, J., Saqqaq: An Inuit Hunting Community in the Modern World. 2000: University of Toronto Press.

[31] Boutayeb, A., The double burden of communicable and non-communicable diseases in developing countries. Trans R Soc Trop Med Hyg, 2006; 100(3):p. 191-9.

[32] Doak CM, Adair LS, Bentley M, Monteiro C, Popkin BM. The dual burden household and the nutrition transition paradox. Int J Obes (Lond), 2005; 29 (1):p. 129-36. 
[33] Monteiro, C.A., W.L. Conde, and B.M. Popkin, The burden of disease from undernutrition and overnutrition in countries undergoing rapid nutrition transition: a view from Brazil. Am J Public Health, 2004; 94 (3):p. 433-4.

[34] Benjelloun, S., Nutrition transition in Morocco. Public Health Nutr, 2002; 5: p. 135-40.

[35] Galal, O.M., The nutrition transition in Egypt: obesity, undernutrition and the food consumption context. Public Health Nutr, 2002; 5 (1A):p. 141-8.

[36] Garrett, J.L. and M.T. Ruel, Stunted child-overweight mother pairs: prevalence and association with economic development and urbanization. Food Nutr Bull, 2005; 26 (2):p. 209-21.

[37] WHO / FAO. Expert Consultation. Diet, nutrition and the prevention of chronic diseases.Geneva: World Health Organization. Report of a WHO / FAO Expert Consultation. 2003; Available from: http://www.who.int/dietphysicalactivity/publications/trs916/fr/gsfao_introduction.pdf.

[38] Manton, K.G., The global impact of noncommunicable diseases: estimates and projections. World Health Stat Q, 1988; 41(3-4):p. 255-66.

[39] WHO. The World Health Report: making a Difference. Geneva: World Health Organization. 1999; Available from: chrome-extension: //mhjfbmdgcfjbbpaeojofohoefgiehjai/index.html.

[40] WHO. The World Health Report. Reducing risks, promoting healthy life. Geneva: World Health Organization. 2002; Available from: http://www.who.int/whr/2002/en/whr02_en.pdf?ua=1.

[41] Choi, B., R. Bonita, and D. Mcqueen, The need for global risk factor surveillance. Journal of Epidemiology and Community Health, 2001; 55(6):p. 370.

[42] Leeder S, Raymond S, Greenberg H, Lui H, Esson K. A Race Against Time: the Challenge of Cardiovascular Disease in developing economies. New York: The Center for Global Health and Economic Development, Columbia University, 2004.

[43] Abegunde DO, Mathers CD, Adam T, Ortegon M, Strong K.. The burden and costs of chronic diseases in low-income and middle-income countries. Lancet, 2007; 370(9603):p. 1929-38.

[44] Kengne, A.P. and C.S. Anderson, The neglected burden of stroke in Sub-Saharan Africa. Int J Stroke, 2006; 1(4):p. $180-90$.

[45] Mensah, G.A., A heart-healthy and "stroke-free" world through policy development, systems change, and environmental supports: a 2020 vision for sub-Saharan Africa. Ethn Dis, 2003: 13(2 Suppl 2):p. S4-12.

[46] Vellingiri B, Jayaramayya K, Iyer M, Narayanasamy A, Govindasamy V, Giridharan B, and al. CoVID-19: A promising cure for the global panic. Sci Total Environ, 2020; 725: . 138277.

[47] Phua J, Weng L, Ling L, Egi M, Lim CM, Divatia JV, and al., Intensive care management of coronavirus disease 2019 (COVID-19): challenges and recommendations. Lancet Respir Med, 2020; 8(5):p. 506-517.

[48] Chen J, Lu H, Melino G, Boccia S, Piacentini M, Ricciardi W, and al. COVID-19 infection: the China and Italy perspectives. Cell Death Dis, 2020; 11(6):p. 438.

[49] WHO, WHO announces COVID-19 epidemic a pandemic. World Health Organization, Geneva, Switzerland, 2020. 